\title{
Flexural Strength Analysis of Starch Based Biodegradable Composite Using Areca Frond Fibre Reinforcement
}

\author{
Srinivas Shenoy Heckadka, ${ }^{1}$ Manjeshwar Vijaya Kini, ${ }^{1}$ Raghuvir Pai Ballambat, ${ }^{1}$ \\ Satish Shenoy Beloor, ${ }^{2}$ Sathish Rao Udupi, ${ }^{1}$ and Ullal Achutha Kini ${ }^{1}$ \\ ${ }^{1}$ Department of Mechanical and Manufacturing Engineering, Manipal Institute of Technology, Manipal University, \\ Manipal 576 104, India \\ ${ }^{2}$ Department of Aeronautical and Automobile Engineering, Manipal Institute of Technology, Manipal University, \\ Manipal 576 104, India
}

Correspondence should be addressed to Srinivas Shenoy Heckadka; shenoysrinivas@rediffmail.com

Received 18 June 2014; Accepted 28 October 2014; Published 13 November 2014

Academic Editor: Archie Lockamy

Copyright (C) 2014 Srinivas Shenoy Heckadka et al. This is an open access article distributed under the Creative Commons Attribution License, which permits unrestricted use, distribution, and reproduction in any medium, provided the original work is properly cited.

\begin{abstract}
Natural fibres and biodegradable matrices are being considered nowadays as substitutes to synthetic fibre reinforced polymer composites mainly in sectors where high load carrying capacity and high strength are not prerequisites. Present study utilizes biodegradable matrix composite prepared by varying the weight of the base material (95-170 g), binder (5-10 g), and plasticizer $(5-20 \mathrm{~g})$ with treated areca frond fibres as reinforcement. Contents are transferred to a pneumatic press, compacted, and subjected to curing. Taguchi method with L8 orthogonal array was used to reduce the number of experiments. Specimens for the flexural tests are cut out from the prepared laminates and tests are performed using UTM. Maximum flexural strength of $16.97 \mathrm{MPa}$ was obtained with a combination of base $(170 \mathrm{~g})$, binder $(10 \mathrm{~g})$, and plasticizer $(5 \mathrm{~g})$. Analysis of the results indicated that plasticizer has the maximum effect on flexural strength of the biodegradable composites.
\end{abstract}

\section{Introduction}

1.1. Composites. Composites are novel engineering materials made from two or more constituents that remain separate and distinct on a macroscopic level while forming a single component. There are two categories of constituent materials: matrix and reinforcement. At least one portion of each type is required. The matrix material surrounds and supports the reinforcement by maintaining their relative positions. The reinforcement imparts special physical (mechanical and electrical) properties to enhance the matrix properties [1]. A synergism produces material properties unavailable from naturally occurring materials. Composites provide the designer, fabricator, equipment manufacturer, and consumer with sufficient flexibility to meet the demands presented by different environments and special requirements. Thus composites, due to their heterogeneous composition, provide unique flexibility in design along with other attributes like superior directional properties, high specific strength, and stiffness properties. Manufacturing of composites with complex shapes especially moulding with polymer composites, reparability, corrosion resistance, durability, adaptability, and cost effectiveness has attracted their use in several engineering and other applications [2].

1.2. Biodegradable Composites. Environmental concerns and stricter government regulations on recycling materials pressed scientists to develop new materials mainly from renewable resources. Using natural fibres in biodegradable matrices can give numerous advantages with regard to fibres traditionally used in composites. The attractive features of these fibres are their abundant availability, low cost, light weight, and high specific modulus in contrast to the synthetic fibres. Biodegradable composites are developed with a perspective of sustainability. The concept is to maximize the performance of the blend and deliver the optimal functional 


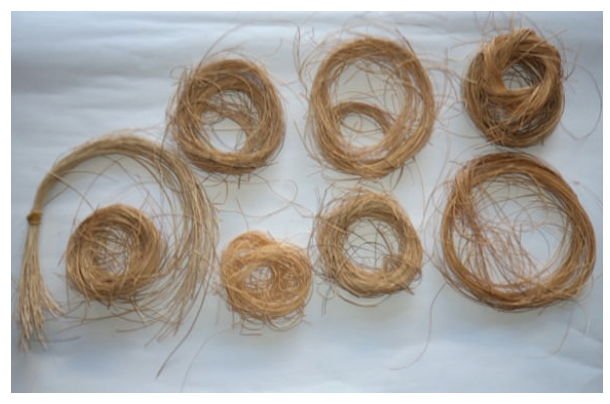

(a)

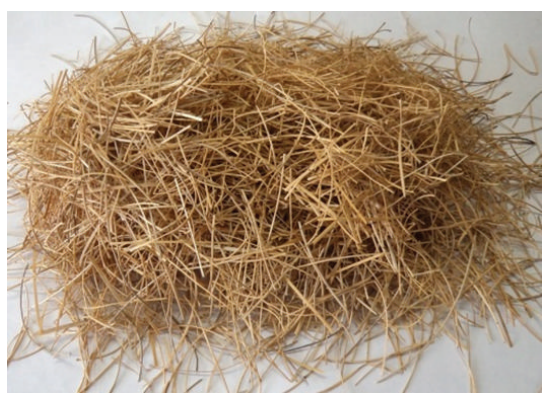

(b)

Figure 1: Areca frond fibre extraction and treatment: (a) extracted fibres; (b) treated fibres.

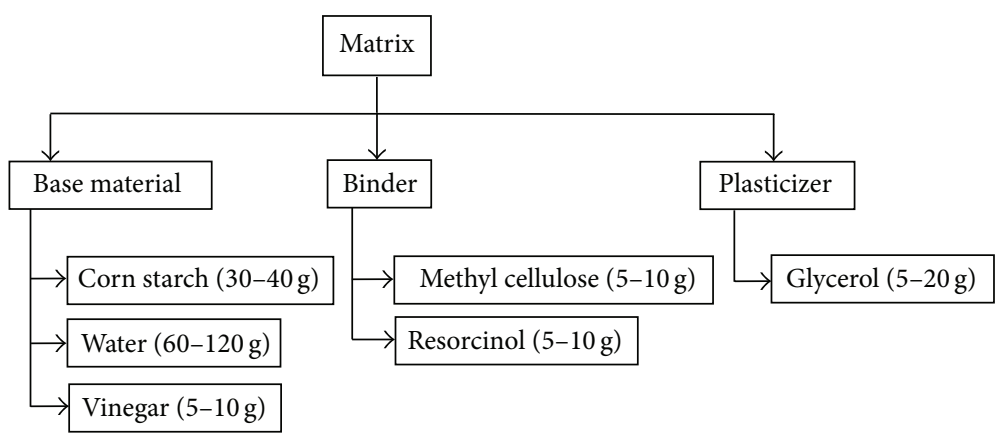

FIgURE 2: Constituents of biodegradable matrix.

requirements. The hydrophilic nature of the natural polymers together with reinforcing strength of the natural fibres results in environment friendly composite materials. Biodegradable composite are formulated by using a suitable matrix (biodegradable resin) and a reinforcement of natural fibres. Natural fibres such as hemp, sisal, kenaf, bamboo, bagasse, areca, and jute along with biodegradable polymers such as polylactic acid (PLA) [3, 4] and polybutylene succinate (PBS) are extensively used as green composites [5].

Normally, natural fibre polymer composites are fabricated by using traditional manufacturing techniques which are designed for conventional fibre reinforced polymer composites and thermoplastics. These techniques include resin transfer moulding, vacuum infusion, compression moulding, direct extrusion, compounding, and injection moulding [6]. However techniques such as compression moulding and hand layup methods have been successfully used for producing biodegradable composites with controllable quality. Venkata Reddy et al. fabricated alkali treated kapok/sisal reinforced polyester composites by hand layup technique [7]. Srinivasababu et al. carried out a study on okra, sisal, and banana fibre reinforced polyester composites using hand layup technique. The variations in mechanical properties and thermal characteristics of these composites are evaluated [8]. Anuar and Zuraida evaluated the improvement in mechanical properties of kenaf bast fibre reinforced thermoplastic elastomer composite using compression moulding technique [9].

1.3. Taguchi Concept. Taguchi method is one of the effective techniques to reduce number of experiments while retaining quality of data collection. The first step in designing the experiments is the proper selection of factors and levels. In the present study, three main factors base material (A), binder (B), and plasticizer (C) in two levels (Level 1 and Level 2) are considered.

Thian et al. have investigated the sintered properties such as sintering temperature, heating rate, holding time, and cooling rate of $\mathrm{Ti}-6 \mathrm{Al}-4 \mathrm{~V} / \mathrm{HA}$ tensile bars using Taguchi method using $\mathrm{L}_{9}$ 3-level orthogonal array [1]. MajdzadehArdakani and Nazari fabricated thermoplastic nanocomposites using melt extrusion technique. The effects of clay cation, water, polyvinyl alcohol, clay contents on clay intercalation, and mechanical properties are also investigated according to the Taguchi experimental design method [10]. Palanikumar studied the influence of drilling parameters such as spindle speed and feed rate on the thrust force, surface roughness, and delamination characteristics of the composites using Taguchi's $\mathrm{L}_{16}$, 4-level orthogonal array [11]. Satapathy et al. have investigated the processing and characterization of epoxy matrix composites reinforced with short flakes obtained from the scales of a typical fresh water fish and also reported erosion wear characteristics. Analysis of variance (ANOVA) is performed and signal to noise $(S / N)$ ratios are determined. Experimental results revealed that the rate of erosion by impact of solid erodent is greatly influenced by various control factors [12]. Pal and Gauri studied the effectiveness of five performance metrics that are used for optimization of multiple response problems. Multiple regression-based weighted signal-to-noise ratio as 


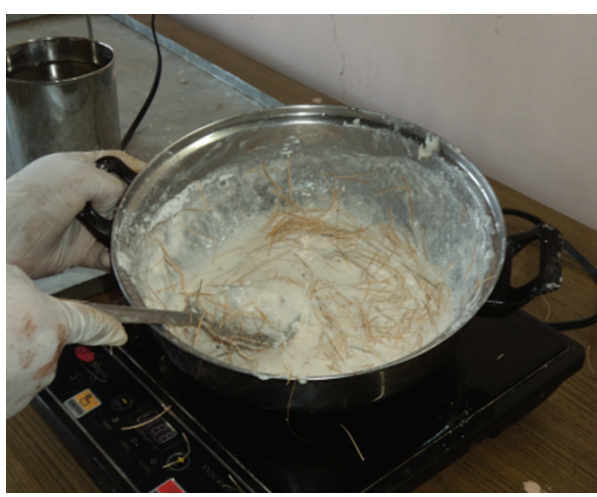

(a)

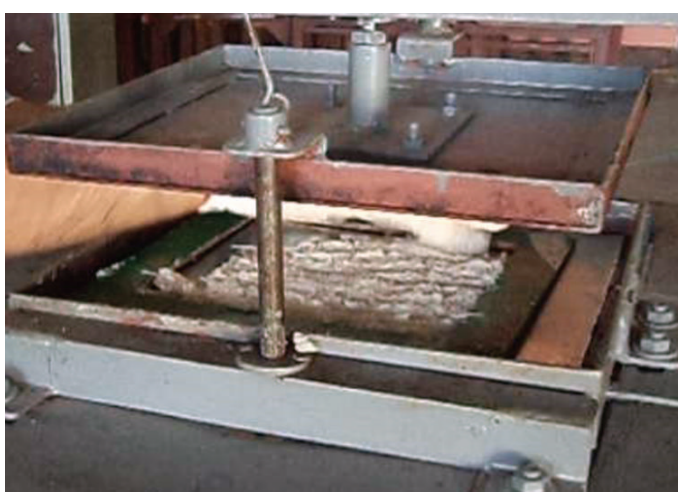

(b)

FIGURE 3: Preparation of biodegradable matrix composites: (a) mixing and heating of matrix constituents; (b) compaction.
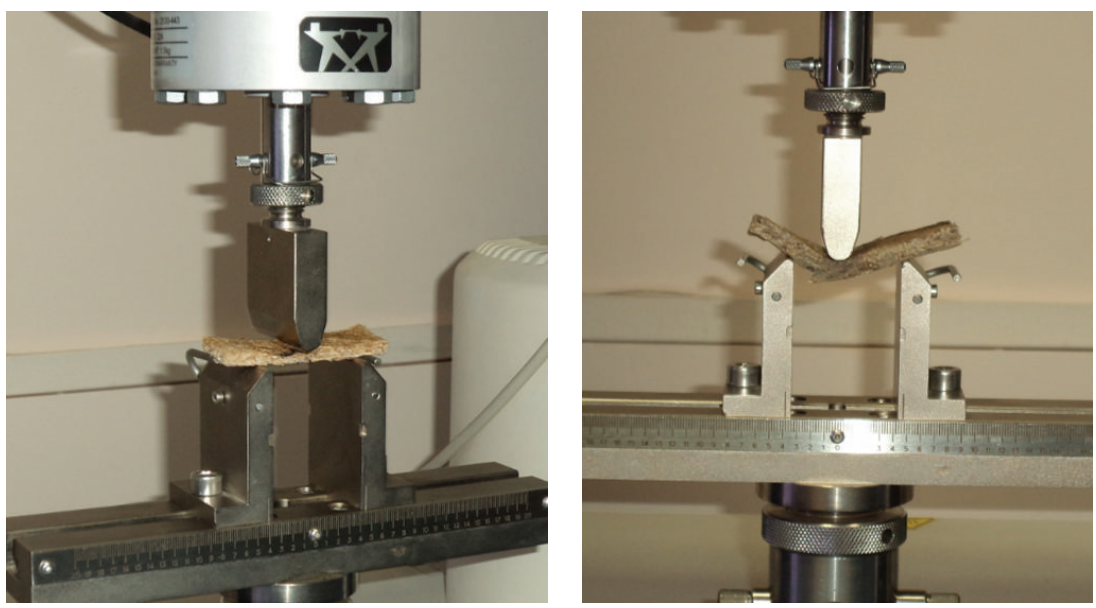

FIGURE 4: Flexural specimen testing.

TABLE 1: Selected factors and their respective levels (coded units).

\begin{tabular}{lcc}
\hline Factors & Level 1 & Level 2 \\
\hline Base material (A) & -1 & +1 \\
Binder (B) & -1 & +1 \\
Plasticizer (C) & -1 & +1 \\
\hline
\end{tabular}

a performance metric is the most effective in finding an optimal solution for multiple response problems [13].

\section{Experimental Details}

2.1. Fibre Extraction and Treatment. Areca fronds are collected from locally available areca plantations. Fronds thus obtained are soaked in water for 4 days. The soaking process loosens the fibres and can be extracted out easily [14]. The Areca frond fibres are separated from the fronds using a wire brush. Finally, the fibers are washed again with fresh water and dried at room temperature. The dried fibres are "untreated fibres." The extracted areca frond fibres are treated
TABLE 2: Taguchi $\mathrm{L}_{8}$ orthogonal array of designed experiments (coded units).

\begin{tabular}{lccc}
\hline \multirow{2}{*}{ Experiment number } & \multicolumn{3}{c}{ Factors } \\
& Base material, A & Binder, B & Plasticizer, C \\
\hline 1 & -1 & -1 & -1 \\
2 & -1 & -1 & +1 \\
3 & -1 & +1 & -1 \\
4 & -1 & +1 & +1 \\
5 & +1 & -1 & -1 \\
6 & +1 & -1 & +1 \\
7 & +1 & +1 & -1 \\
8 & +1 & +1 & +1 \\
\hline
\end{tabular}

TABLE 3: Selected factors and their respective levels (uncoded units).

\begin{tabular}{lcc}
\hline Factors & Level 1 & Level 2 \\
\hline Base material, A (g) & 95 & 170 \\
Binder, B (g) & 5 & 10 \\
Plasticizer, C (g) & 5 & 20 \\
\hline
\end{tabular}



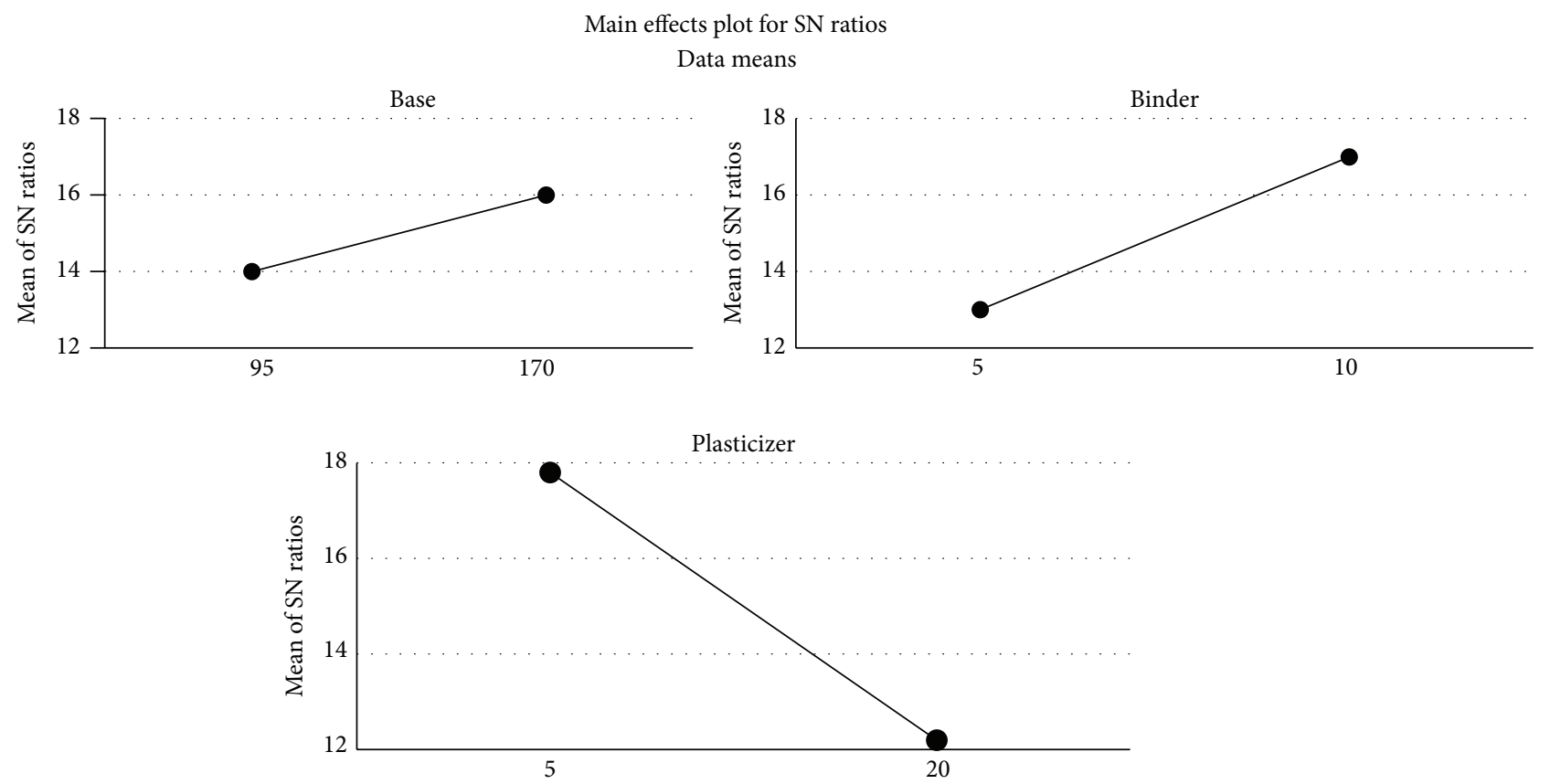

Signal-to-noise: larger is better

Figure 5: Response plot for flexural strength.

TABLE 4: Taguchi $\mathrm{L}_{8}$ orthogonal array of designed experiments (uncoded units).

\begin{tabular}{|c|c|c|c|c|}
\hline \multirow{2}{*}{ Experiment number } & \multirow{2}{*}{ Combination of factors and levels } & \multicolumn{3}{|c|}{ Factors } \\
\hline & & Base material, A (g) & Binder, B (g) & Plasticizer, C (g) \\
\hline 1 & $\mathrm{~A} 1 \mathrm{~B} 1 \mathrm{Cl}$ & 95 & 5 & 5 \\
\hline 2 & $\mathrm{~A} 1 \mathrm{~B} 1 \mathrm{C} 2$ & 95 & 5 & 20 \\
\hline 3 & $\mathrm{~A} 1 \mathrm{~B} 2 \mathrm{C} 1$ & 95 & 10 & 5 \\
\hline 4 & $\mathrm{~A} 1 \mathrm{~B} 2 \mathrm{C} 2$ & 95 & 10 & 20 \\
\hline 5 & $\mathrm{~A} 2 \mathrm{~B} 1 \mathrm{C} 1$ & 170 & 5 & 5 \\
\hline 6 & $\mathrm{~A} 2 \mathrm{~B} 1 \mathrm{C} 2$ & 170 & 5 & 20 \\
\hline 7 & $\mathrm{~A} 2 \mathrm{~B} 2 \mathrm{Cl}$ & 170 & 10 & 5 \\
\hline 8 & $\mathrm{~A} 2 \mathrm{~B} 2 \mathrm{C} 2$ & 170 & 10 & 20 \\
\hline
\end{tabular}

TABLE 5: S/N ratios for different characteristics.

\begin{tabular}{lcc}
\hline$S / N$ ratio & Description & Equation \\
\hline Larger is better & $\begin{array}{c}\text { Maximize the } \\
\text { response }\end{array}$ & $S / N_{i}=-10 \log \left(\sum\left(1 / Y_{u}{ }^{2}\right) / N_{i}\right)$ \\
\hline Smaller is better & $\begin{array}{c}\text { Minimize the } \\
\text { response }\end{array}$ & $S / N_{i}=-10 \log \left(\sum\left(Y_{u}{ }^{2}\right) / N_{i}\right)$ \\
\hline
\end{tabular}

Note: $i=$ experiment number; $u=$ trial number; $N_{i}=$ number of trials for experiment $i$.

with $1 \mathrm{~N}$ solution of $\mathrm{Na}_{2} \mathrm{CO}_{3}$ where the total volume of solution was 10 times the weight of the fibres. The fibers are kept in this alkaline solution for $12 \mathrm{~h}$ at room temperature. Finally fibres are dried at room temperature for $48 \mathrm{~h}$ to get the "alkali treated fibres" [15]. Figure 1 shows the extracted and treated areca fibres. Chemical composition of areca frond fibres is Hemi cellulose (35-64.8\%), Lignin (13-24.8\%), and ash (4-4.4\%) [16].

2.2. Matrix Preparation. Figure 2 shows the basic ingredients of the biodegradable matrix.

The preparation of biodegradable matrix starts by weighing the constituents of the Base material (corn starch powder, water, and vinegar). The weighed ingredients are then transferred into a mixing vessel and evenly mixed by using a magnetic stirrer. Binders (methyl cellulose and resorcinol) and plasticizer (glycerol) are added to the mix and stirred for about 15 minutes. Further the mixture is transferred to a steel vessel and heated at $140^{\circ} \mathrm{C}$ until it turns into a semisolid paste [14]. As the matrix mixture turns into a semisolid paste the fibres are added to the mix and the contents are transferred to a mould $(300 \mathrm{~mm} \times 300 \mathrm{~mm})$ and spread evenly to obtain a homogenous distribution using hand layup 
TABLE 6: Flexural strength results.

\begin{tabular}{lccccc}
\hline Experiment number & $\begin{array}{c}\text { Combination of } \\
\text { factors and levels }\end{array}$ & $\begin{array}{c}\text { Fase A } \\
\text { (Wt. grams) }\end{array}$ & $\begin{array}{c}\text { Binder B } \\
\text { (Wt. grams) }\end{array}$ & $\begin{array}{c}\text { Plasticizer C } \\
\text { (Wt. grams) }\end{array}$ & $\begin{array}{c}\text { Rerage maximum flexural } \\
\text { strength (MPa) }\end{array}$ \\
\hline 1 & A1B1C1 & 95 & 95 & 95 & 10.48 \\
2 & A1B1C2 & 95 & 95 & 170 & 4.59 \\
3 & A1B2C1 & 95 & 170 & 95 & 6.49 \\
4 & A1B2C2 & 95 & 170 & 95 & 3.38 \\
5 & A2B1C1 & 170 & 95 & 170 & 4.13 \\
6 & A2B1C2 & 170 & 170 & 95 & 2.81 \\
7 & A2B2C1 & 170 & 170 & 170 & 16.97 \\
\hline
\end{tabular}

TABLE 7: Response table for signal-to-noise ratios.

\begin{tabular}{lccc}
\hline \multicolumn{3}{c}{ Larger is better } \\
Level & Base (A) & Binder (B) & Plasticizer (C) \\
\hline 1 & 14.42 & 13.04 & 17.70 \\
2 & 15.58 & 16.97 & 12.31 \\
Delta & 1.16 & 3.93 & 5.39 \\
Rank & 3 & 2 & 1 \\
\hline
\end{tabular}

technique. Figure 3 shows the preparation of biodegradable matrix composites. The mix is compacted to form sheets using pneumatic press. The inner walls of the mould are coated with a thin layer of wax as a release agent. Further composites are cured in a hot chamber (steam heating) at $85^{\circ} \mathrm{C}$ for $24 \mathrm{~h}$.

2.3. Designing the Experiment. In this study, main factors considered are base material (A), binder (B), and plasticizer (C) in two levels (Table 1). The factors and their levels have been selected based on past literature, practical aspects, and results of screening tests. For Taguchi method with three factors and two levels for each factor, a standard $\mathrm{L}_{8}$ orthogonal array is employed as shown in Table 2. The uncoded units of Taguchi $\mathrm{L}_{8}$ orthogonal array are provided in Tables 3 and 4. Flexural strength is used for response calculations.

2.4. Signal-to-Noise $(S / N)$ Ratio. The Taguchi method is commonly used to verify the robustness of products. The method helps to identify control factors that reduce variability by minimizing the effects of uncontrollable factors. Taguchi method often uses a 2-step optimization process. In step 1 use the $S / N$ ratio to identify those control factors that reduce variability. In step 2, identify control factors that bring the mean to target and have little or no effect on the $S / N$ ratio. The signal-to-noise $(S / N)$ ratio measures how the response varies relative to the nominal or target value under different noise conditions. Table 5 shows the $S / N$ ratios for different characteristics. For the present study, "larger is better aspect" is considered.
2.5. Flexural Testing. Composite specimens are tested for flexural strength according to ASTM D 790 [17, 18]. Experiments are performed using Universal Testing Machine and Instron (Model 3366). Test specimens with dimensions $64 \times$ $12 \times 5 \mathrm{~mm}$ and cross head speed of $2 \mathrm{~mm} / \mathrm{min}$ are used. Figure 4 shows the UTM test rig.

\section{Results and Discussion}

Results of the flexural strength tests performed on the fabricated biodegradable matrix composite are given in Table 6 .

The maximum value of flexural strength is $16.97 \mathrm{MPa}$ and minimum value is $2.81 \mathrm{MPa}$.

Based on ranking of the factors using Taguchi analysis, plasticizer has the maximum effect (Table 7). Ranking obtained by Taguchi method points out that plasticizer is ranked 1 followed by binder (rank 2) and base material (rank $3)$.

Referring to Figure 5 the graph for Base material is very close to being parallel to mean line, indicating that it has a very low effect on the flexural strength. Both Binder and Plasticizer have steep slopes indicating that they are important factors contributing to increase in flexural strength.

\section{Conclusions}

The conclusions are as follows.

(i) Optimal combination of the factors and levels for the biodegradable matrix composite is base material $(170 \mathrm{~g})$, binder $(10 \mathrm{~g})$, and plasticizer $(5 \mathrm{~g})$.

(ii) The flexural strength of the laminate obtained suggests that the laminate could be used to fabricate products like pen stand, packaging boxes, and similar products.

\section{Conflict of Interests}

The authors declare that there is no conflict of interests regarding the publication of this paper. 


\section{References}

[1] E. S. Thian, N. H. Loh, K. A. Khor, and S. B. Tor, "Microstructures and mechanical properties of powder injection molded Ti-6Al-4V/HA powder," Biomaterials, vol. 23, no. 14, pp. 29272938, 2002.

[2] J. P. Davim, "Study of drilling metal-matrix composites based on the Taguchi techniques," Journal of Materials Processing Technology, vol. 132, no. 1-3, pp. 250-254, 2003.

[3] B. Bax and J. Müssig, "Impact and tensile properties of PLA/Cordenka and PLA/flax composites," Composites Science and Technology, vol. 68, no. 7-8, pp. 1601-1607, 2008.

[4] S. Ochi, "Mechanical properties of kenaf fibers and kenaf/PLA composites," Mechanics of Materials, vol. 40, no. 4-5, pp. 446$452,2008$.

[5] T. H. Nam, S. Ogihara, N. H. Tung, and S. Kobayashi, "Effect of alkali treatment on interfacial and mechanical properties of coir fiber reinforced poly(butylene succinate) biodegradable composites," Composites B: Engineering, vol. 42, no. 6, pp. 16481656, 2011.

[6] M.-P. Ho, H. Wang, J.-H. Lee et al., "Critical factors on manufacturing processes of natural fibre composites," Composites Part B: Engineering, vol. 43, no. 8, pp. 3549-3562, 2012.

[7] G. Venkata Reddy, S. Venkata Naidu, T. Shobha Rani, and M. C. S. Subha, "Compressive, chemical resistance, and thermal studies on kapok/sisal fabrics polyester composites," Journal of Reinforced Plastics and Composites, vol. 28, no. 12, pp. 1485-1494, 2009.

[8] N. Srinivasababu, K. Murali Mohan Rao, and J. Suresh Kumar, "Experimental determination of tensile properties of okra, sisal and banana fiber reinforced polyester composites," Indian Journal of Science and Technology, vol. 2, no. 7, pp. 35-38, 2009.

[9] H. Anuar and A. Zuraida, "Improvement in mechanical properties of reinforced thermoplastic elastomer composite with kenaf bast fibre," Composites Part B: Engineering, vol. 42, no. 3, pp. 462-465, 2011.

[10] K. Majdzadeh-Ardakani and B. Nazari, "Improving the mechanical properties of thermoplastic starch/poly (vinyl alcohol)/clay nanocomposites," Composites Science and Technology, vol. 70, no. 10, pp. 1557-1563, 2010.

[11] K. Palanikumar, "Experimental investigation and optimisation in drilling of GFRP composites," Measurement, vol. 44, no. 10, pp. 2138-2148, 2011.

[12] A. Satapathy, A. Patnaik, and M. K. Pradhan, "A study on processing, characterization and erosion behavior of fish (Labeorohita) scale filled epoxy matrix composites," Materials and Design, vol. 30, no. 7, pp. 2359-2371, 2009.

[13] S. Pal and S. K. Gauri, "Assessing effectiveness of the various performance metrics for multi-response optimization using multiple regression," Computers and Industrial Engineering, vol. 59, no. 4, pp. 976-985, 2010.

[14] R. P. Swamy, G. C. M. Kumar, Y. Vrushabhendrappa, and V. Joseph, "Study of areca-reinforced phenol formaldehyde composites," Journal of Reinforced Plastics and Composites, vol. 23, no. 13, pp. 1373-1382, 2004.

[15] N. H. Padmaraj, M. Vijaya Kini, B. Raghuvir Pai, B. Sathish Shenoy, and Krishnamoorthy, "Effect of different treatment media on the breaking strength of long Areca nut fibers," in Proceedings of the 4th National Conference on Trends in Mechanical Engineering (TIME '10), pp. 30-33, 2010.
[16] C. V. Srinivasa, A. Arifulla, N. Goutham et al., "Static bending and impact behaviour of areca fibers composites," Materials and Design, vol. 32, no. 4, pp. 2469-2475, 2011.

[17] B.-H. Lee, H.-J. Kim, and W.-R. Yu, "Fabrication of long and discontinuous natural fiber reinforced polypropylene biocomposites and their mechanical properties," Fibers and Polymers, vol. 10, no. 1, pp. 83-90, 2009.

[18] M. M. Kabir, H. Wang, K. T. Lau, F. Cardona, and T. Aravinthan, "Mechanical properties of chemically-treated hemp fibre reinforced sandwich composites," Composites Part B: Engineering, vol. 43, no. 2, pp. 159-169, 2012. 

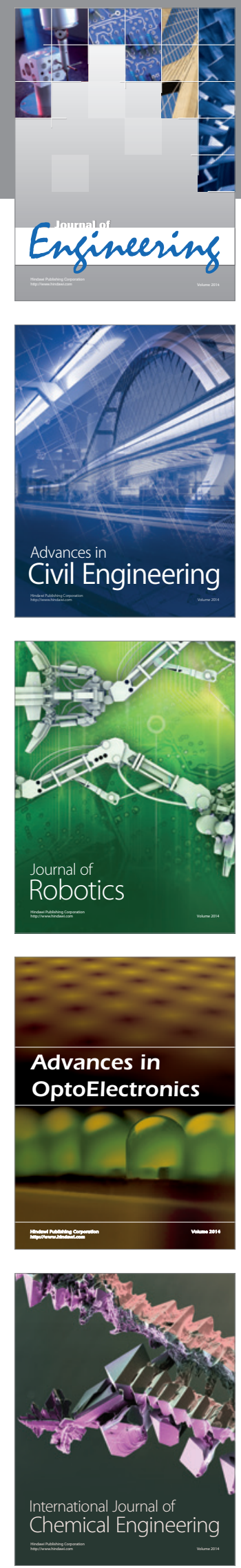

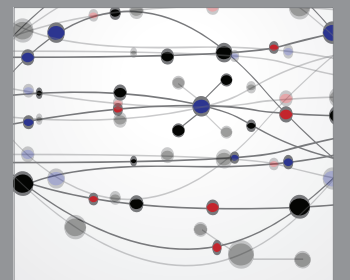

The Scientific World Journal
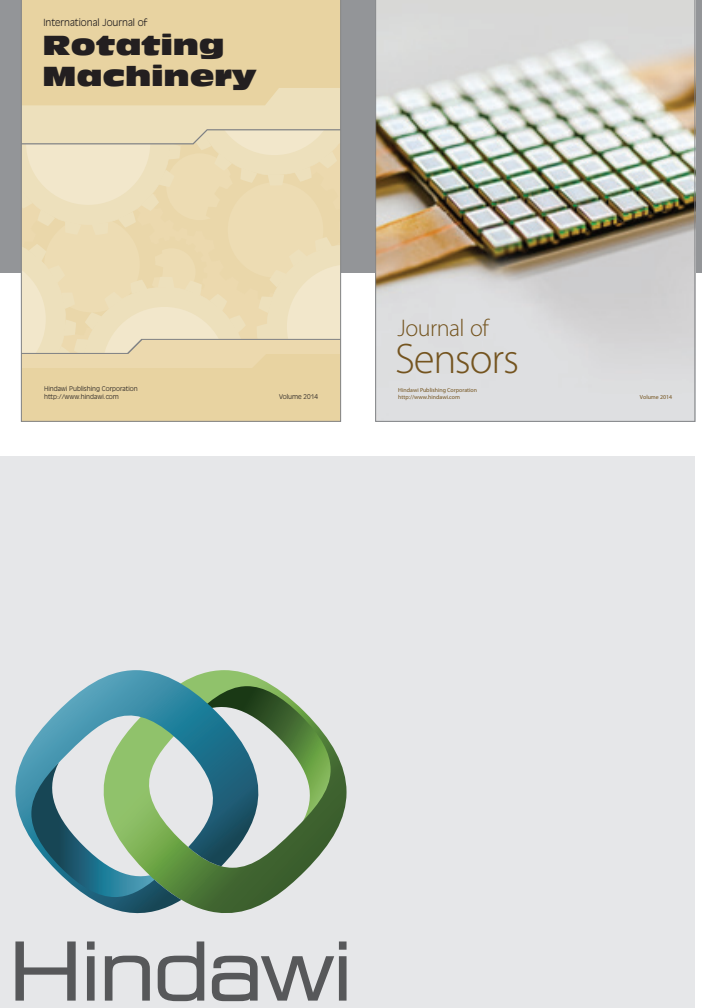

Submit your manuscripts at http://www.hindawi.com
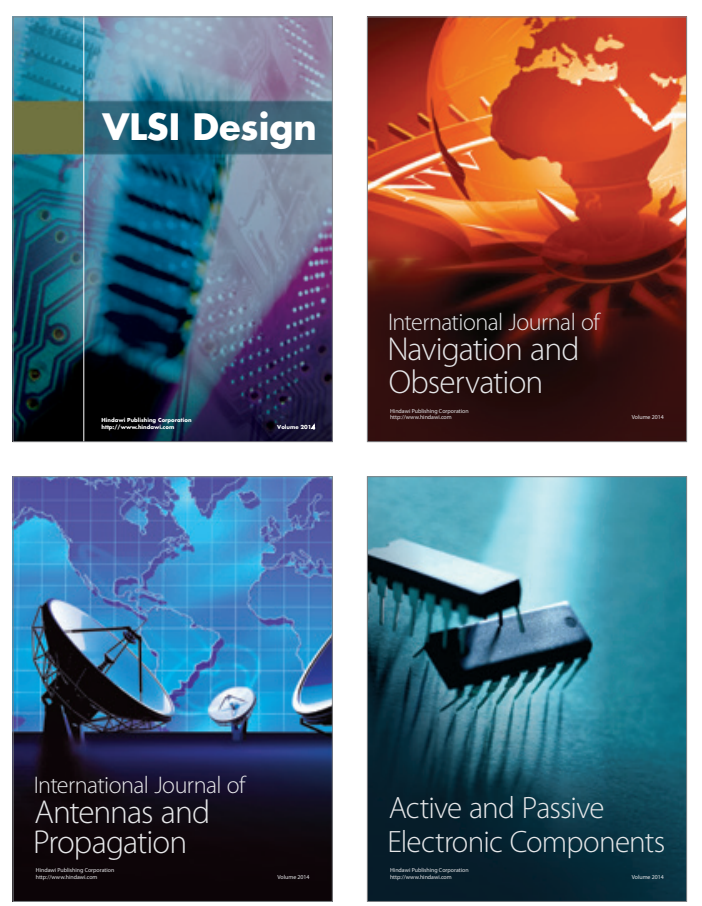
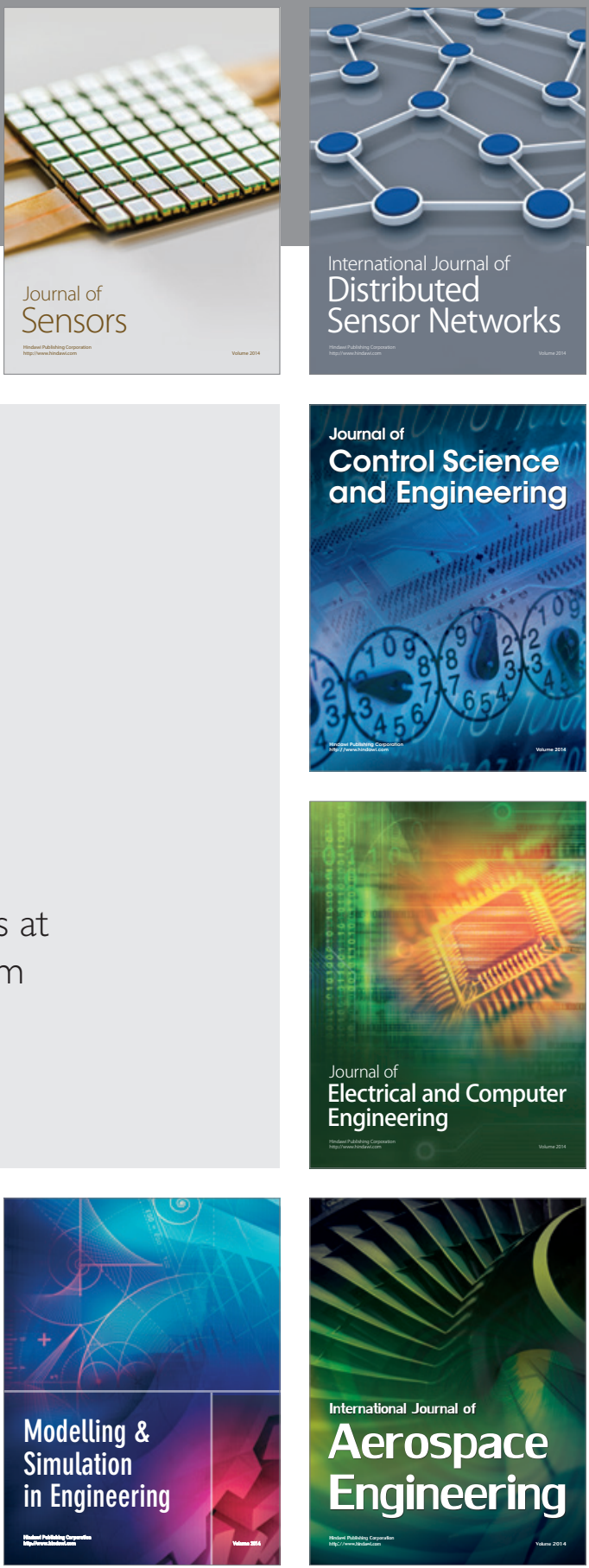

Journal of

Control Science

and Engineering
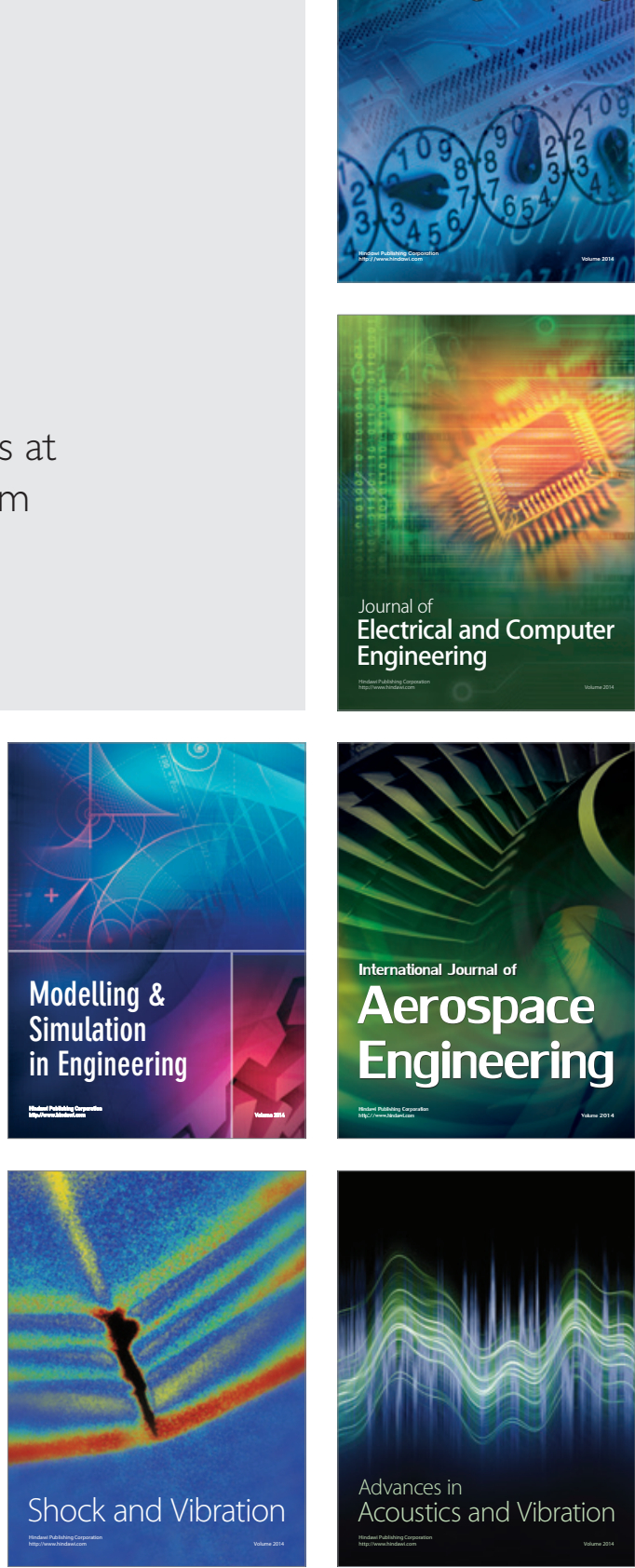